\title{
Influence of Positional Changes of Arms and Legs to Electrocardiogram
}

\author{
Joo-Eun Song ${ }^{1, \S}$, Min-Ju Song ${ }^{1,}$, Ye-Sul Kim ${ }^{1}$, Ha-Nuel Yang ${ }^{1}$, \\ Ye-Jin Lee ${ }^{1}$ and Dongju Jung ${ }^{1,2, \dagger}$ \\ ${ }^{l}$ Department of Biomedical Laboratory Science, College of Life and Health Sciences, \\ Hoseo University, Asan, Chungnam 31499, Korea \\ ${ }^{2}$ The Research Institute for Basic Science, Hoseo University, Asan, Chungnam 31499, Korea
}

\begin{abstract}
Electrocardiogram (ECG) is a widely used method to diagnose electrical activity of heart. Although it is a reliable and easy method, ECG could be interfered by electrical signals. One of the interfering signals is electromyogram (EMG) that is caused by muscle contraction in any parts of the body except heart. To avoid the EMG noise, an examinee is advised to be relaxed on supine position while measuring ECG. Sometimes, patients who can't put their arms and legs down on bed due to some reasons such as cast on arms or legs necessarily have the EMG noise. But detailed information about how much of the noise could be induced by positional change of arms and legs has not been reported. Here we examined the noise by analyzing ECG data from 14 candidates, 7 males and 7 females. The ECG data was obtained using the standard 12 lead ECG. EMG noise was induced by raising arms and legs at $90^{\circ}, 60^{\circ}$ or $30^{\circ}$. Because arms are located close to the heart, noise by the raised arms was analyzed toward left or right arm separately. All of the examinees showed similar pattern of the EMG noise. EMG noise by positional change of left or right arm was clearly monitored in different limb leads. Change of leg positions induced the noise that was monitored in aVF of augmented leads and II and III of limb leads. There was a difference in degree of the noise between male and female examinees. In addition to the EMG noise, decrease of PR interval was monitored in particular positional changes, which was prominent in male examinees. These results will enlarge fundamental understanding about EMG noise in ECG.
\end{abstract}

Key Words: Electrocardiogram, Electromyogram, PR interval

\section{서 론}

심전도(electrocardiogram, ECG)는 사람의 체표면에서 심 장의 전기적 활성도를 고통 없이 측정할 수 있는 검사 방 법이다. 사용이 간단하고 심장과 관련된 여러 지표를 측 정할 수 있어서 많은 병원에서 1 차적인 심장질환의 진단 에 사용하고 있다. 심전도 측정기는 심장근육에서 발생하 는 탈분극과 재분극의 전기적인 과정을 받아들인 뒤 이를
증폭해서 그래프로 나타내는 장비이다. 이 장비를 이용하 여 심전도를 측정함으로써 심장의 박동, 리듬 및 심장 내 전기 흐름을 확인할 수 있다. 그러므로 심전도를 측정함으 로 부정맥, 심장 내부 구조의 변화, 심낭질환, 전해질 불균 형, 중독, 전도계통의 이상 등을 감지할 수 있다(Simonson, 1958). 특히 고령화 인구의 빠른 증가로 인해 심장질환의 발생이 높아지고 있지만, 보통 사전징후를 보이지 않는 경 우가 많기 때문에 심장질환의 진단에 심전도의 중요성은 더욱 크다고 할 수 있다.

\footnotetext{
* Received: January 26, 2018 / Accepted: March 6, 2018

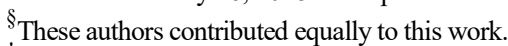

${ }^{\dagger}$ Corresponding author: Dongju Jung. Department of Biomedical Laboratory Science, College of Life and Health Sciences, Hoseo University, Asan, Chungnam 31499, Korea.

Tel: +82-41-540-9969, Fax:+82-41-540-9997, e-mail: djjungg@hoseo.edu

(C) The Korean Society for Biomedical Laboratory Sciences. All rights reserved.

(C) This is an Open Access article distributed under the terms of the Creative Commons Attribution Non-Commercial License (http://creativecommons.org/licenses/by-nc/3.0/) which permits unrestricted non-commercial use, distribution, and reproduction in any medium, provided the original work is properly cited.
} 
현재 사용중인 심전도 장비는 네덜란드의 생리학자 에 인트호벤(Willem Einthoven)이 개발한 현선전류계(String galvanometer)에 기반하며 이 방법을 통해 현재 사용중인 $\mathrm{P}, \mathrm{Q}, \mathrm{R}, \mathrm{S}$ 및 $\mathrm{T}$ 파형이 확립되었다. 에인트호벤의 개발 이 후 토마스 루이스(Thomas Lewis)와 다른 연구자들이 심장 앞에서의 단극유도법을 개발하였다(Burch, 1978). 프랭크 윌슨(Frank Wilson) 등은 $\mathrm{VR}, \mathrm{VL}, \mathrm{VF}$ 의 단극팔다리 유도를 개발하였고 후에 엠마누엘 골드버거(Emmanuel Goldberger) 가 윌슨의 방법을 $50 \%$ 더 증폭시켜 증폭(augmented) 단 극팔다리 유도를 개발하였다(Planck, 1945). 현재는 이 방 법들을 종합한 표준12유도 심전도법이 사용되고 있다. 심 전도는 간편히 심장의 전기적 상태를 측정할 수 있는 안 정된 방법이지만 파형에 영향을 미칠 수 있는 요인들이 존재한다. 여기에는 땀이나 피부 분비물로 인한 전극접촉 이 느슨해지거나, 몸 위의 털로 인한 접촉불량, 환자의 움 직임이나 호흡 등으로 인한 바닥선 동요, 전자기장의 간 섭으로 인한 바닥선 동요, 인공심장보조기 착용자에서 발 생하는 간섭파형 등이 있다. 그래서 이러한 간섭을 없애 기 위해 심전도 측정 시 대상자는 심신이 안정되는 것 뿐 만 아니라 실내의 온도, 습도 및 광도 등으로부터도 영향 을 받지 않는 상태에서 심전도 측정을 받아야 한다. 이러 한 외부 조건과는 상관없이 운동 중에 심전도를 측정하는 경우나, 질병으로 인해 어쩔 수 없이 몸의 떨림이 있는 경 우에 근전도(electromyogram, EMG) 혼입이 발생한다. 파킨 슨병이나 알코올금단증상, 분노, 다발성 경화증, 마약류의 복용 등의 환자에서의 근전도 혼입이 그 예가 될 수 있다. 또한 팔다리 등에 깁스를 하거나 마비 등으로 앙와위 자 세(supine position)를 유지하기 힘든 경우에도 근전도 혼입 이 있을 수 있다. 하지만 이러한 팔다리의 자세 변화가 어 느 정도의 크기로 어떤 유도에서 근전도 혼입을 일으키는 지는 조사된 적이 없다. 우리는 이 논문에서 팔다리의 자 세 변화가 어떤 형태로 심전도에 영향을 미치는지 조사하 고자 하였다. 좌, 우 각각의 팔의 자세를 변화시키고 여 기에 다리 자세의 변화를 더해서 심전도를 측정하였다. 표준12유도를 통해 얻어진 결과는 심전도 용지를 이용하 여 $0.1 \mathrm{mV}$ 이상의 근전도 파형의 혼입부터 시작하여 0.1 $\mathrm{mV}$ 씩 증가할 때마다 한 단계 높은 근전도 혼입으로 표 시하였다. 실험의 결과를 통해 좌, 우 팔의 자세 변화가 어느 유도에서 근전도 혼입을 일으키는지, 어느 정도의 각 도에서 가장 큰 근전도 혼입이 일어나는지는 확인하였다. 아울러 근전도 혼입에 남녀 간 차이가 있는 것을 확인하 였고, 특히 남성의 경우에서 근전도 혼입 시 $\mathrm{PR}$ 간격(PR interval)의 감소가 확인되었다. 이 결과를 통해 좌, 우 팔 과 다리의 자세 변화에 따른 근전도 혼입의 양상을 정량 적으로 파악하였고 이를 바탕으로 향후 임상검사에서 팔 다리 움직임이 자유롭지 못한 환자를 대상으로 심전도 검 사 시 참고자료로 사용될 수 있을 것이라 판단된다. 아울 러 근전도 혼입이 특정 심전도 간격에도 영향을 미칠 수 있다는 것을 사실을 발견하였다.

\section{재료 및 방법}

심전도 측정은 20 대 남녀 각 7명씩을 대상으로 실시하 였다. 대상자는 자율적으로 참여하였으며 사전에 실험에 대한 설명을 들었고 실험에 동의하였다. 모든 실험은 호 서대학교 생명윤리위원회의 기준에 맞추어 실시하였다. 실 험을 통해 얻어진 개인정보는 모두 익명 처리하였으며 실 험 외에 다른 목적으로 사용하지 않았다.

심전도 측정을 위해서 $\mathrm{GE}$ 사의 $\mathrm{Mac} 2000$ 심전도 기기 를 이용하여 표준12유도를 측정하였다. 전극의 부착은 손 목 위쪽 10 15 cm, 발목 위쪽 10 15 cm에 팔다리 전극을 부착하였고, 가슴전극은 다음과 같이 부착하였다. V1 전극 은 넷째 갈비뼈, 복장 뼈 오른쪽에 부착, V2 전극은 넷째 갈비뼈, 복장 뼈 왼쪽에 부착, V4 전극은 다섯째 갈비뼈, 빗장뼈 중간 선에 부착하고 $\mathrm{V} 2$ 와 $\mathrm{V} 4$ 를 부착한 중간에 $\mathrm{V} 3$ 전극을 부착하였다. V6 전극을 V4와 수평이 되도록 왼 겨드랑이 선에 부착하였고, V5 전극은 V4와 V6사이에 수 평으로 부착하였다.

피검자는 머리부분과 다리부분이 각각 $30^{\circ}$ 상승되도록 조정된 침대에 앙와위 자세로 누운 상태로 심전도 측정을 하였으며, 특히 손과 발이 침대 밖으로 벗어나지 않도록 주의하였다. 피검자는 5 분 간 누워 안정을 취한 뒤 심전도 측정을 하였다. 근전도 혼입을 위한 실험을 위해서는 전 극을 부착하고 왼팔, 오른팔, 양쪽 팔을 손가락까지 편 상 태로 각각 $90^{\circ}, 60^{\circ}, 30^{\circ}$ 들어올린 후 그 자세를 10 초 간 유지한 상태에서 각각의 심전도를 측정하였다. 다리 각도 는 다리와 발이 일직선이 되도록 $90^{\circ}, 60^{\circ}, 30^{\circ}$ 들어올린 후 자세를 10 초 간 유지한 상태에서 각각의 심전도를 측 정하였다. 팔의 각도는 어깨 선을 기준으로 측정하였고 다리의 각도는 대퇴골을 기준으로 측정하였다.

근전도 혼입에 대한 평가는 다음과 같은 방식으로 하였 다. 앙와위 자세에서 측정된 심전도를 기준으로 각 유도 에서 근전도 혼입에 의한 전위차이가 없을 경우 (-)로 표 시하였다. 바닥선을 중심으로 $0.1 \mathrm{mV}$ 이하의 범위에서 근 


\section{(A)}
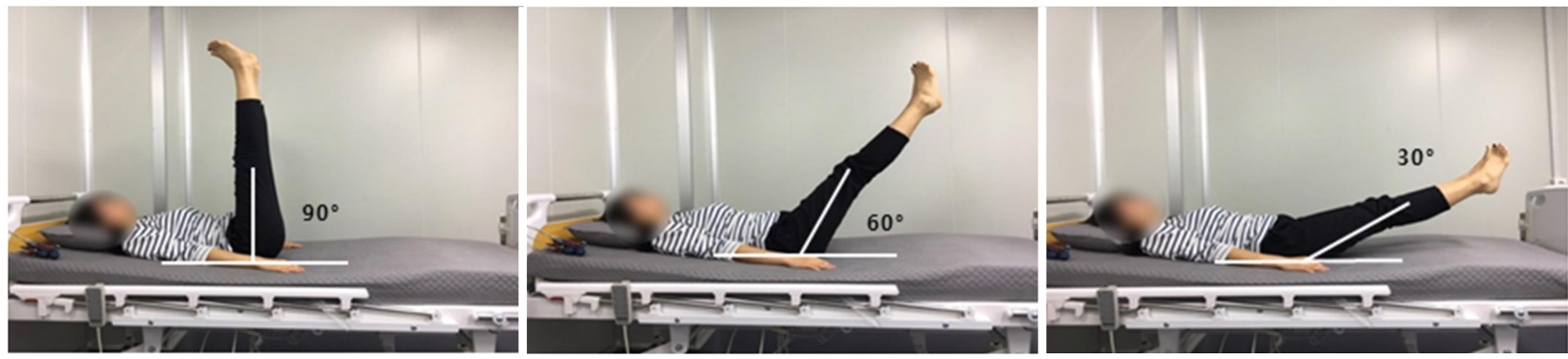

\section{B}
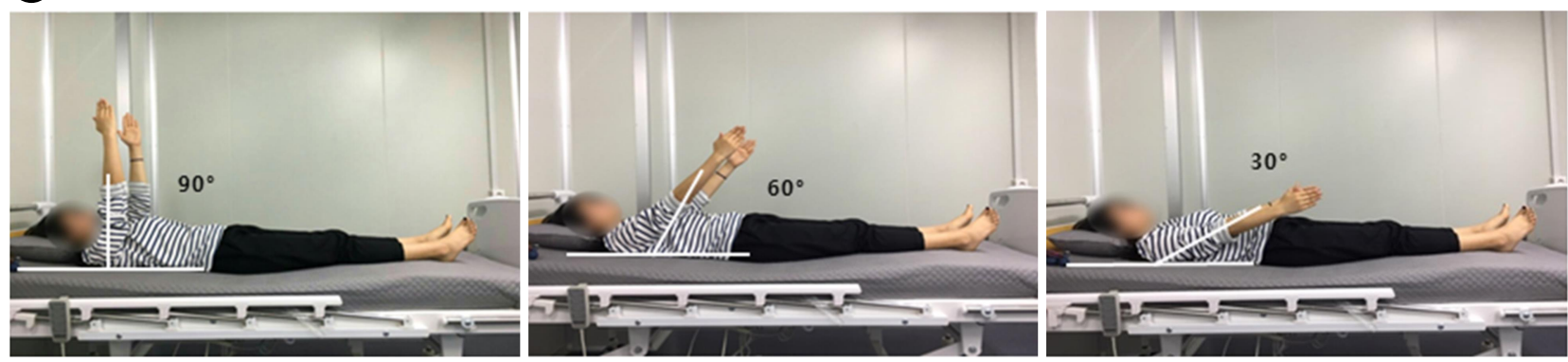

Fig. 1. Positional changes of arms and legs.

전도 혼입이 있을 경우 $(+), 0.1 \mathrm{mV}$ 초과 $0.2 \mathrm{mV}$ 이하의 범위에서 근전도 혼입이 있을 경우 $(++), 0.2 \mathrm{mV}$ 초과 $0.3 \mathrm{mV}$ 이하의 범위에서 근전도 혼입이 있을 경우 (+1+), $0.3 \mathrm{mV}$ 초과 범위에서 근전도 혼입이 있을 경우 (+1+1) 로 표시하였다.

심전도 파형의 분석을 위해서 $\mathrm{RR}$ 간격, $\mathrm{QRS}$ 간격, $\mathrm{PR}$ 간격, QT 간격을 측정하였다. 앙와위 상태에서 측정된 심 전도 간격과 비교하여 팔 또는 다리의 자세 변화를 통해 각 간격에서 증가 또는 감소가 있을 경우 $t$ 검정을 통해 통계적인 차이가 있는지를 확인하였다. 분석에 사용된 간 격들은 모든 유도에서 측정하였고 평균값을 구하여 비교 하였다.

\section{결 과}

\section{근전도 혼입 측정을 위한 자세}

근전도 혼입을 유도하기 위해 팔과 다리를 $90^{\circ}, 60^{\circ}, 30^{\circ}$ 씩 들어올렸다(Fig. 1). 팔의 경우 좌우를 함께 들어올리거 나 따로 구분하여 들어올렸고, 다리의 경우는 좌우를 함 께 들어올렸다. 팔다리 움직임에 의해 바닥선의 동요가 크게 발생하기 때문에 해당 자세에서 10 초 정도 유지하여 바닥선을 안정시킨 상태에서 심전도를 측정하였다. 이러
한 방법으로 측정 시 심전도 각 유도에서 근전도가 혼입 된 것을 확인할 수 있었다(Fig. 2).

\section{팔다리 자세 변화에 따른 근전도 혼입 양상}

각각의 팔다리 자세를 취했을 때 혼입되는 근전도의 전 위 값을 앙와위 자세에서의 전위와 비교하여 변화된 전위 차 $(\mathrm{mV})$ 를 정량적으로 표시하였다. 오른쪽 팔을 각각 $90^{\circ}$, $60^{\circ}, 30^{\circ}$ 들어올렸을 때 팔다리유도 I과 II 유도에서 근전 도 혼입이 발견되었고 III 유도에서는 혼입이 측정되지 않 았다. 단극유도에서는 $\mathrm{aVL}$ 보다 $\mathrm{aVR}$ 유도에서의 근전도 혼입이 뚜렷하였다. 왼쪽 팔을 각각 $90^{\circ}, 60^{\circ}, 30^{\circ}$ 들어올 렸을 때 팔다리유도 I과 III에서 근전도 혼입이 발견되었 고 II 유도에서는 혼입이 측정되지 않았다. 단극유도에서 는 오른쪽 팔을 들어올렸을 때와 반대로 왼쪽 팔을 들어 올렸을 때는 $\mathrm{aVR}$ 보다 $\mathrm{aVL}$ 유도에서의 근전도 혼입이 뚜 렷하였다. 가슴유도에서는 왼쪽 팔을 $60^{\circ}, 30^{\circ}$ 들어올렸을 때 V5와 V6 유도에서 근전도 혼입이 증가되었다. 양쪽 팔을 모두 들어올렸을 경우 $60^{\circ}, 30^{\circ}$ 에서 V5와 V6 유도에 서 측정된 근전도 혼입에 더해서 $\mathrm{V} 3$ 와 $\mathrm{V} 4$ 유도에서도 근 전도 혼입이 증가하는 것을 관찰하였다. 양쪽 팔을 $90^{\circ}$ 를 들어올렸을 경우에서도 한쪽 팔만 들어올린 경우와는 다 르게 V6에서 근전도 혼입이 증가하였다(Table 1-A). 양쪽 
다리를 각각 $90^{\circ}, 60^{\circ}, 30^{\circ}$ 들어올린 경우 팔다리유도에서 는 II와 III 유도에서 근전도 혼입이 뚜렷하였고, $60^{\circ}, 30^{\circ}$ 를 들어올린 경우에서 더 뚜렷하게 관찰되었다. 단극유도 에서는 $\mathrm{aVF}$ 에서 근전도 혼입이 뚜렷하게 관찰되었고 $30^{\circ}$ 를 들어올린 경우에 근전도 혼입이 모든 단극유도에서 증 가하였다. 가슴유도에서는 $\mathrm{V} 4, \mathrm{~V} 5, \mathrm{~V} 6$ 유도에서 근전도 혼입이 뚜렷하였다(Table 1-A).

\section{근전도 혼입의 남녀 차}

남성과 여성에서의 팔다리 자세 변화에 따른 근전도 혼입을 비교하기 위해 남녀의 결과를 따로 떼어내어 비 교하였다. 전반적으로 남성에서의 근전도 혼입이 여성보 다 큰 것을 확인할 수 있었다. 표준팔다리 유도에서 왼쪽 팔을 들었을 때의 II 유도와 오른팔을 들었을 때의 III 유
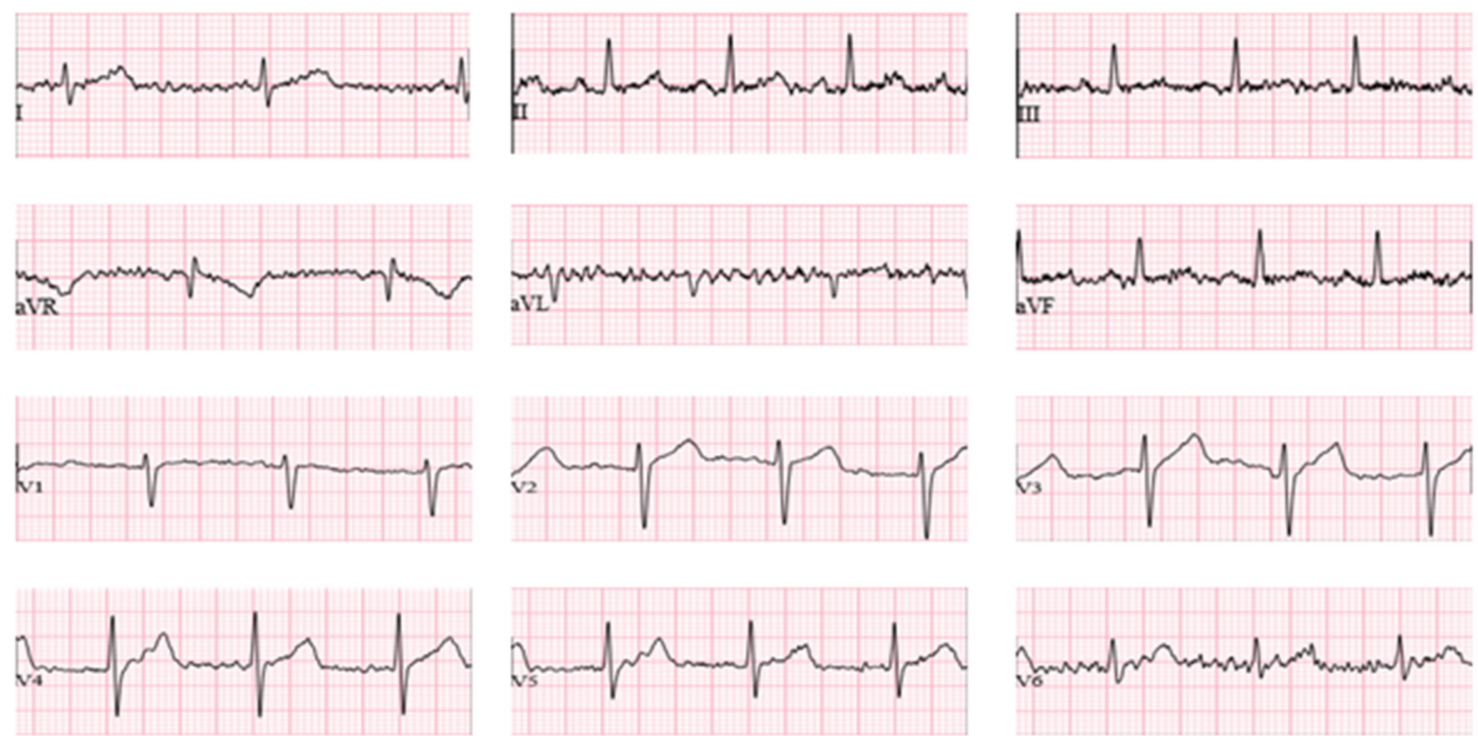

Fig. 2. A Representative ECG recording have EMG (Electromyogram) noise.

Table 1. EMG noise recorded by a standard 12-lead ECG

(A)

\begin{tabular}{|c|c|c|c|c|c|c|c|c|c|c|c|c|}
\hline Mean & I & II & III & $\mathrm{aVL}$ & aVR & $\mathrm{aVF}$ & V1 & $\mathrm{V} 2$ & V3 & V4 & V5 & V6 \\
\hline Normal & - & - & - & - & - & - & - & - & - & - & - & - \\
\hline LA9 $90^{\circ}$ & ++ & - & ++ & ++ & + & + & + & + & + & + & + & + \\
\hline LA $60^{\circ}$ & +++ & - & ++ & ++ & + & + & + & + & + & + & ++ & ++ \\
\hline $\mathrm{LA} 30^{\circ}$ & +++ & - & +++ & ++ & + & + & + & + & + & + & ++ & ++ \\
\hline RA90 ${ }^{\circ}$ & ++ & ++ & - & + & ++ & + & + & + & + & + & + & + \\
\hline RA $60^{\circ}$ & ++ & ++ & - & + & ++ & + & + & + & + & + & + & + \\
\hline RA30 & ++ & ++ & - & + & ++ & ++ & + & + & + & + & + & + \\
\hline RLA90 ${ }^{\circ}$ & ++ & ++ & ++ & ++ & ++ & + & + & + & + & + & + & ++ \\
\hline RLA $60^{\circ}$ & +++ & ++ & ++ & ++ & ++ & ++ & + & + & + & ++ & ++ & ++ \\
\hline $\operatorname{RLA} 30^{\circ}$ & +++ & ++ & +++ & ++ & ++ & ++ & + & + & $H$ & ++ & ++ & ++ \\
\hline RLL90 ${ }^{\circ}$ & + & ++ & ++ & + & + & ++ & + & + & + & + & ++ & ++ \\
\hline RLL60 ${ }^{\circ}$ & + & +++ & +++ & + & + & +++ & + & + & + & ++ & ++ & ++ \\
\hline RLL30 $0^{\circ}$ & + & +++ & +++ & ++ & ++ & +++ & + & + & + & ++ & ++ & ++ \\
\hline
\end{tabular}


Table 1. Continued

(B)

\begin{tabular}{|c|c|c|c|c|c|c|c|c|c|c|c|c|}
\hline Female & I & II & III & $\mathrm{aVL}$ & aVR & $\mathrm{aVF}$ & V1 & $\mathrm{V} 2$ & V3 & V4 & V5 & V6 \\
\hline Normal & - & - & - & - & - & - & - & - & - & - & - & - \\
\hline LA $90^{\circ}$ & ++ & - & + & + & - & - & - & - & - & - & + & + \\
\hline LA $60^{\circ}$ & ++ & - & ++ & + & + & - & - & - & - & + & + & + \\
\hline $\operatorname{LA} 30^{\circ}$ & +++ & - & +++ & ++ & + & + & + & + & + & + & + & ++ \\
\hline $\mathrm{RA}^{\circ} 0^{\circ}$ & + & + & - & - & + & + & - & - & - & - & - & - \\
\hline RA $60^{\circ}$ & ++ & + & - & - & ++ & + & - & - & - & - & - & - \\
\hline RA30 & ++ & ++ & - & + & + & + & + & - & - & + & + & + \\
\hline RLA90 ${ }^{\circ}$ & ++ & + & + & + & ++ & + & - & - & - & - & + & + \\
\hline RLA $60^{\circ}$ & ++ & ++ & ++ & ++ & ++ & + & + & + & + & + & + & + \\
\hline $\operatorname{RLA} 30^{\circ}$ & ++ & ++ & ++ & ++ & ++ & ++ & + & + & + & + & ++ & ++ \\
\hline RLL90 ${ }^{\circ}$ & - & ++ & ++ & + & + & ++ & - & - & - & + & + & + \\
\hline $\operatorname{RLL}^{\circ} 0^{\circ}$ & - & +++ & +++ & + & + & +++ & + & + & + & ++ & ++ & ++ \\
\hline $\operatorname{RLL} 30^{\circ}$ & + & +++ & +++ & ++ & ++ & +++ & + & + & + & + & ++ & ++ \\
\hline
\end{tabular}

(C)

\begin{tabular}{|c|c|c|c|c|c|c|c|c|c|c|c|c|}
\hline Male & I & II & III & $\mathrm{aVL}$ & aVR & $\mathrm{aVF}$ & V1 & V2 & V3 & V4 & V5 & V6 \\
\hline Normal & - & - & - & - & - & - & - & - & - & - & - & - \\
\hline LA90 ${ }^{\circ}$ & ++ & - & ++ & ++ & + & + & + & + & + & + & + & ++ \\
\hline LA $60^{\circ}$ & +++ & - & +++ & ++ & + & + & + & + & + & ++ & ++ & ++ \\
\hline $\operatorname{LA} 30^{\circ}$ & +++ & - & +++ & ++ & + & + & + & + & + & ++ & ++ & ++ \\
\hline $\mathrm{RA}^{\circ} 0^{\circ}$ & ++ & ++ & - & + & ++ & + & + & + & + & + & + & + \\
\hline RA $60^{\circ}$ & +++ & +++ & - & + & +++ & ++ & + & + & + & ++ & + & + \\
\hline $\mathrm{RA} 30^{\circ}$ & +++ & +++ & - & ++ & +++ & ++ & ++ & + & + & + & + & + \\
\hline RLA90 ${ }^{\circ}$ & ++ & ++ & ++ & ++ & ++ & ++ & + & + & + & + & ++ & ++ \\
\hline RLA $60^{\circ}$ & +++ & +++ & +++ & +++ & +++ & ++ & ++ & ++ & ++ & ++ & ++ & ++ \\
\hline $\operatorname{RLA} 30^{\circ}$ & +++ & +++ & +++ & +++ & +++ & ++ & ++ & ++ & ++ & ++ & ++ & +++ \\
\hline RLL90 ${ }^{\circ}$ & + & ++ & +++ & ++ & ++ & +++ & + & + & + & ++ & ++ & ++ \\
\hline RLL60 ${ }^{\circ}$ & + & +++ & +++ & ++ & + & ++ & + & + & ++ & ++ & ++ & +++ \\
\hline RLL30 ${ }^{\circ}$ & ++ & +++ & +++ & ++ & ++ & +++ & + & + & + & ++ & ++ & ++ \\
\hline
\end{tabular}

Normal indicates remaining in supine position. RA and LA indicate right arm and left arm respectively. RLA indicates both of right and left arms. RLL indicates both of right and left legs. The numbers next to the RA, LA, RLA, and RLL indicate angles of arms and legs raised. $(-)$ indicates no EMG noise, $(+)$ indicates EMG noise of $0.1 \mathrm{mV}$.

도에서는 남성에서도 근전도 혼입이 관찰되지 않았다. 여 성에서 근전도 혼입이 나타나지 않았던 단극유도와 가슴 유도의 경우에서는 $0.1 \mathrm{mV}$ 이하 정도의 근전도 혼입이 증 가된 것이 남성에게서 관찰되었다(Table 1-B, C).

\section{근전도 혼입에 따른 심전도 간격의 변화}

근전도 혼입이 이루어졌을 경우, 심전도 파형의 간격에 영향을 미치는지 확인하였다. 이를 위해 RR 간격, $\mathrm{QRS}$ 


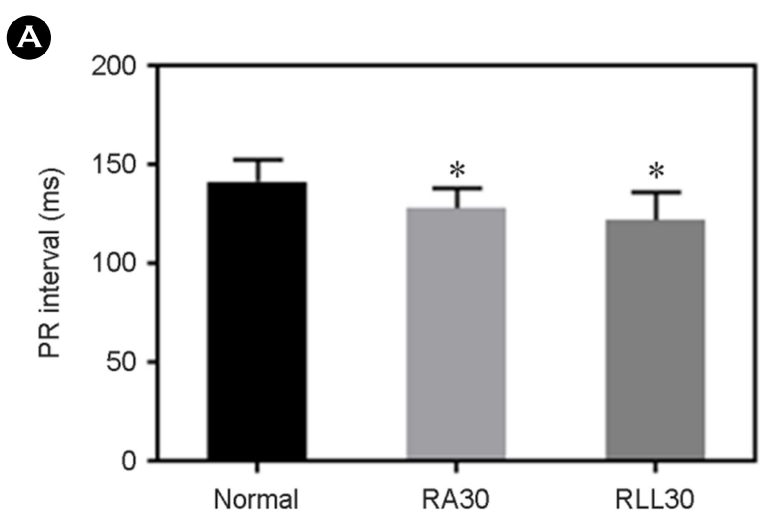

B

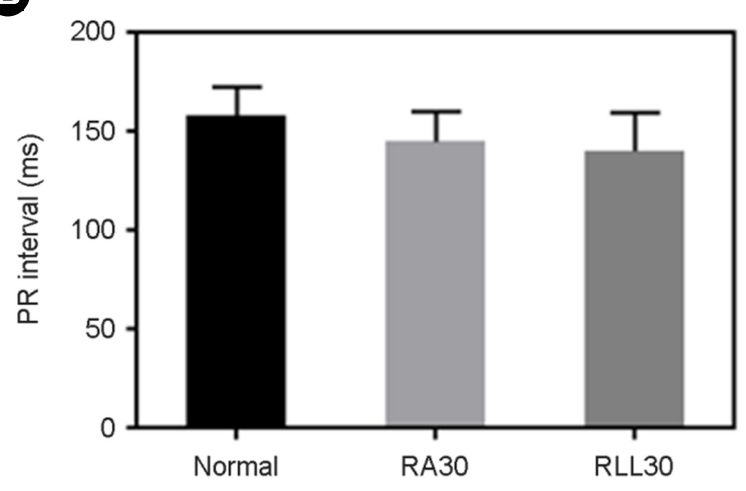

C

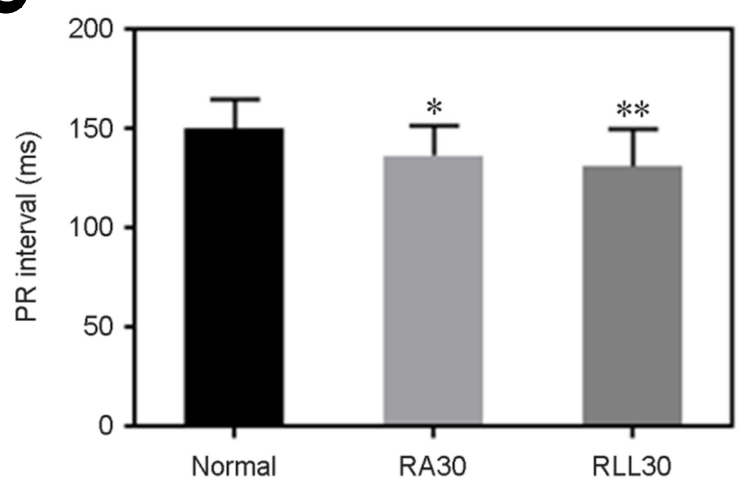

Fig. 3. $P R$ interval decrease by EMG noise. normal indicates remaining in supine position, RA30 indicates raise of right arm at 30 degree, and RLL30 indicates raise of right and left legs at 30 degree.

간격, $\mathrm{PR}$ 간격, QT 간격을 측정하여 앙와위 상태에서 측 정된 심전도 간격과 비교하였다. 비교를 통해 시간 변화 가 통계적 유의성을 갖는지를 $t$ 검정으로 분석하여 $P$ 값 으로 나타내었다. $P$ 값이 0.05 이하인 경우는 유의적 차이 가 있는 것으로 판명하였고, 0.01 이하인 경우는 매우 유 의적 차이가 있는 것으로 판명하였다. 오른팔이나 양다리
를 $30^{\circ}$ 들었을 경우 남성에서 $\mathrm{PR}$ 간격이 줄어드는 것이 확인되었다(Fig. 3A). 여성에서도 오른팔이나 양다리를 $30^{\circ}$ 들었을 경우 $\mathrm{PR}$ 간격이 줄어드는 것이 보이나 통계적으 로 유의하지는 않았다(Fig. 3B). 남녀 결과를 합하여 분석 할 경우, 양다리를 $30^{\circ}$ 들었을 경우 $\mathrm{PR}$ 간격이 줄어드는 것의 통계적 유의성이 높아졌다(Fig. $3 \mathrm{C}$ ). 비록 PR 간격이 줄어들었지만 양다리를 $30^{\circ}$ 들어올려도 $\mathrm{RR}$ 간격의 변화 에는 영향을 미치지 못하였다(Data not shown).

\section{고 찰}

심전도 측정 시 혼입되는 근전도는 정상적인 측정을 방 해하는 신호이다. 반대로 근전도 측정 시에도 심전도의 혼입이 문제가 되어 이를 제거하는 방법도 보고되었다 $(\mathrm{Lu}$ et al., 2009). 심전도 측정 시 근전도의 혼입을 막기 위한 방법으로는 환자의 상태를 안정적으로 하는 것이 가장 일 반적이다. 하지만 근육의 움직임이 발생하는 질환을 가지 고 있는 환자나 엠블런스에서 심전도를 측정할 경우에서 는 어쩔 수 없이 근전도 혼입이 발생하므로 기기적으로 근전도 혼입을 걸러내는 여러 가지 방법들이 개발되었다 (Cherkassky and Kilts, 2001; Blanco-Velasco et al., 2008; Mithun et al., 2011). 일반적으로 임상에서 진단용으로 사용하는 표준12유도 심전도 기기는 근전도 혼입이 발생할 수 있 으므로 팔 또는 다리의 위치 변화가 얼마만큼의 근전도를 유발하고, 혼입된 근전도의 특이성을 이해한다면 정확한 심전도 결과 판독에 많은 도움을 줄 수 있을 것이다. 이번 실험의 결과 팔의 위치 변화가 있는 경우에서는 좌측 팔 인지 아니면 우측 팔인지에 따라 근전도 혼입이 서로 다 른 심전도 유도에서 측정되는 것을 확인하였다. 이는 팔 다리 유도 측정법의 측정원리에 정확히 부합하는 결과이 다. 다리의 위치 변화를 유도할 경우에는 심전도 측정전 극은 왼쪽에, 접지전극은 오른쪽 다리에 부착하므로 팔의 위치 변화와는 다르게 좌우 차를 확인하기 어려워 두 다 리를 모두 함께 드는 방식으로 실험을 진행하였다. 이 경 우 단극유도의 $\mathrm{aVF}$, 팔다리유도의 II와 III 유도 등 다리 쪽 방향의 축을 가지고 있는 유도에서 근전도 혼입이 잘 측정되는 것을 확인할 수 있었다. 그리고 가슴유도의 경 우에서는 더 좌측에 위치한 V4, V5 그리고 V6 유도에서 더 큰 근전도 혼입이 나타난 것이 특징이었다. 그러므로 어느 유도에서 근전도가 혼입되는지를 확인한다면 팔다리 어느 부위의 근육에서 근전도가 발생하는지를 예측 가능 하게 된다. 
체표면에서 기록되는 근전도의 혼입은 심전도 용지의 넓은 부위에 걸쳐 작고 연속적인 파형을 만든다. 이 형태 는 $\mathrm{QRS}$ 군에 집중되어 큰 한 개의 파형을 생성하는 심전 도 파형과 크게 구분된다(Gabriel et al., 2007). 그래서 근전 도 혼입은 파형의 형태를 보고 쉽게 구분해낼 수 있으며 그 혼입의 크기는 파형의 크기로 분석이 가능하다. 그 예 로 근육이 상대적으로 더 많은 남성에게서 같은 각도의 팔다리 위치 변화에도 근전도 혼입이 여성보다 높게 나타 난 것을 들 수 있다. 남성에게서 근전도 혼입 시 심전도 $\mathrm{PR}$ 간격이 줄어드는 것은 기존에 알려지지 않았던 특징 이다. 이러한 남녀 간의 차이는 근전도 혼입뿐만 아니라 유전자의 단일염기다형성(single nucleotide polymorphism, $\mathrm{SNP}$ )과 특정 형질의 연관성에서도 나타나는 것을 확인할 수 있다(Jin and Jung, 2015). 하지만 줄어든 간격이 정상 간 격에서 벗어날 정도로 감소하지는 않은 것으로 나타났다. $\mathrm{PR}$ 간격(interval)은 심방의 탈분극을 나타내는 P파의 시작 부터 심실의 탈분극을 나타내는 $\mathrm{Q}$ 파의 시작 전까지의 시 간을 나타내며 정상적으로 $120 \mathrm{~ms}$ (millisecond)의 기간을 갖는다. PR 간격이 매우 짧아지는 경우는 동맥의 상처나 심막염의 경우에 발생하는 것으로 보고되었다(Pedley et al., 2002). 이번 실험에서 근전도 혼입에 의한 PR 간격의 감 소는 측정되었으나 RR 간격은 일정한 것으로 보아 심장 박동이 증가해서 짧아진 것은 아닌 것으로 판단된다. 특 히 PR 간격의 감소는 오른팔이나 양다리를 $30^{\circ}$ 들었을 경우에서만 측정되었고, 왼팔을 $30^{\circ}$ 들었을 경우에서는 감 소가 발생하지 않은 것이 특징적인 결과이다.

이번 실험 결과는 심전도 측정 시 발생할 수 있는 근전 도 혼입의 양상을 팔다리의 움직임을 통해 정량적으로 나 타내었다. 저자들은 이 결과를 통해 임상에서 심전도 측 정 시 근전도 혼입에 대한 판단 기준을 세울 수 있으며, 남녀 간의 근전도 혼입의 차이가 있음을 정량적으로 밝혔 고, 근전도 혼입으로 인해 심전도의 특정 간격의 감소가 발생할 수 있음을 밝혔다.

\section{ACKNOWLEDGEMENTS}

None.

\section{CONFLICT OF INTEREST}

The authors declare that they have no competing interests.

\section{REFERENCES}

Blanco-Velasco M, Weng B, Barner KE. ECG signal denoising and baseline wander correction based on the empirical mode decomposition. Comput Biol Med. 2008. 38: 1-13.

Burch GE. History of precordial leads in electrocardiography. European Journal of Cardiology. 1978. 8: 207-236.

Cherkassky V, Kilts S. Myopotential denoising of ECG signals using wavelet thresholding methods. Neural Networks. 2001 14: 1129-1137.

Gabriel DA, Lester SM, Lenhardt SA, Cambridge ED. Analysis of surface EMG spike shape across different levels of isometric force. Journal of Neuroscience Methods. 2007. 159: 146-152.

Jin HS, Jung DJ. Gender-specific Association of the ANO1 Genetic Variations with Hypertension. Biomedical Science Letters. 2015. 21: 144-151.

Lu G, Brittain JS, Holland P, Yianni J, Green AL, Stein JF, Aziz TZ, Wang S. Removing ECG noise from surface EMG signals using adaptive filtering. Neuroscience Letters. 2009. 462: 14 -19 .

Mithun P, Pandey PC, Sebastian T, Mishra P, Pandey VK. A wavelet based technique for suppression of EMG noise and motion artifact in ambulatory ECG. Conference Proceedings IEEE Engineering in Medicine Biology Society. 2011. 2011: 7087 -7090 .

Pedley DK, Brett C, Nicho N. P-R segment depression: an early diagnostic feature in acute pericarditis: a telephone survey of UK accident and emergency departments. European Journal of Emergency Medicine. 2002. 9: 43-45.

Planck EH. The electrocardiogram; history and clinical application. Journal of the Medical Association of the State of Alabama. 1945. 15: 181.

Simonson E. The normal variability of the electrocardiogram as a basis for differentiation between normal and abnormal in clinical electrocardiography. American Heart Journal. 1958. 55: 80-103.

https://doi.org/10.15616/BSL.2018.24.1.43

Cite this article as: Song JE, Song MJ, Kim YS, Yang HN, Lee YJ, Jung D. Influence of Positional Changes of Arms and Legs to Electrocardiogram. Biomedical Science Letters. 2018. 24: 43-49. 